\title{
Standardization of Herbal Formulations at Molecular Level
}

\author{
Juwairiya Butt ${ }^{1}$, Saiqa Ishtiaq ${ }^{1}$, Bushra ljaz², Zulfiqar Ali Mir ${ }^{3}$, Shumaila Arshad $^{4}$ and Sophia Awais ${ }^{4}$ \\ ${ }^{1}$ Department of Pharmacognosy, Punjab University College of Pharmacy, Lahore, Pakistan \\ ${ }^{2}$ Functional Genomics Lab, Center of Excellence in Molecular Biology, Lahore, Pakistan \\ ${ }^{3}$ Department of Bioinformatics, Center of Excellence in Molecular Biology, Lahore, Pakistan \\ ${ }^{4}$ Faculty of Pharmacy, The University of Lahore, Lahore, Pakistan
}

Received date: January 29, 2018; Accepted date: February 07, 2018; Pulished date: February 12, 2018

\section{Retraction Note:}

The article entitled"Standardization of Herbal Formulations at Molecular Level" has been accepted for publication in the Journal of Pharmacognosy \& Natural Products considering the statements in the article as personal opinion of the author which was found not having any conflict or biasness towards anything. As the article was perspective one, information provided by the author was considered as an opinion to be expressed through publication.

Soon after the publication of the paper, we witnessed some serious concerns and many of them argued that the paper is a personal perspective and had not discussed any relevant ethical issue considered under the journal scope. Moreover, the paper is neither innovative nor thought provoking.

Publisher took decision to make the article online solely based on the reviewers suggestion which considered the article not but a personal opinion of the author. However, it is found that the article has some unavoidable mistakes and issues, therefore, being retracted from the journal.

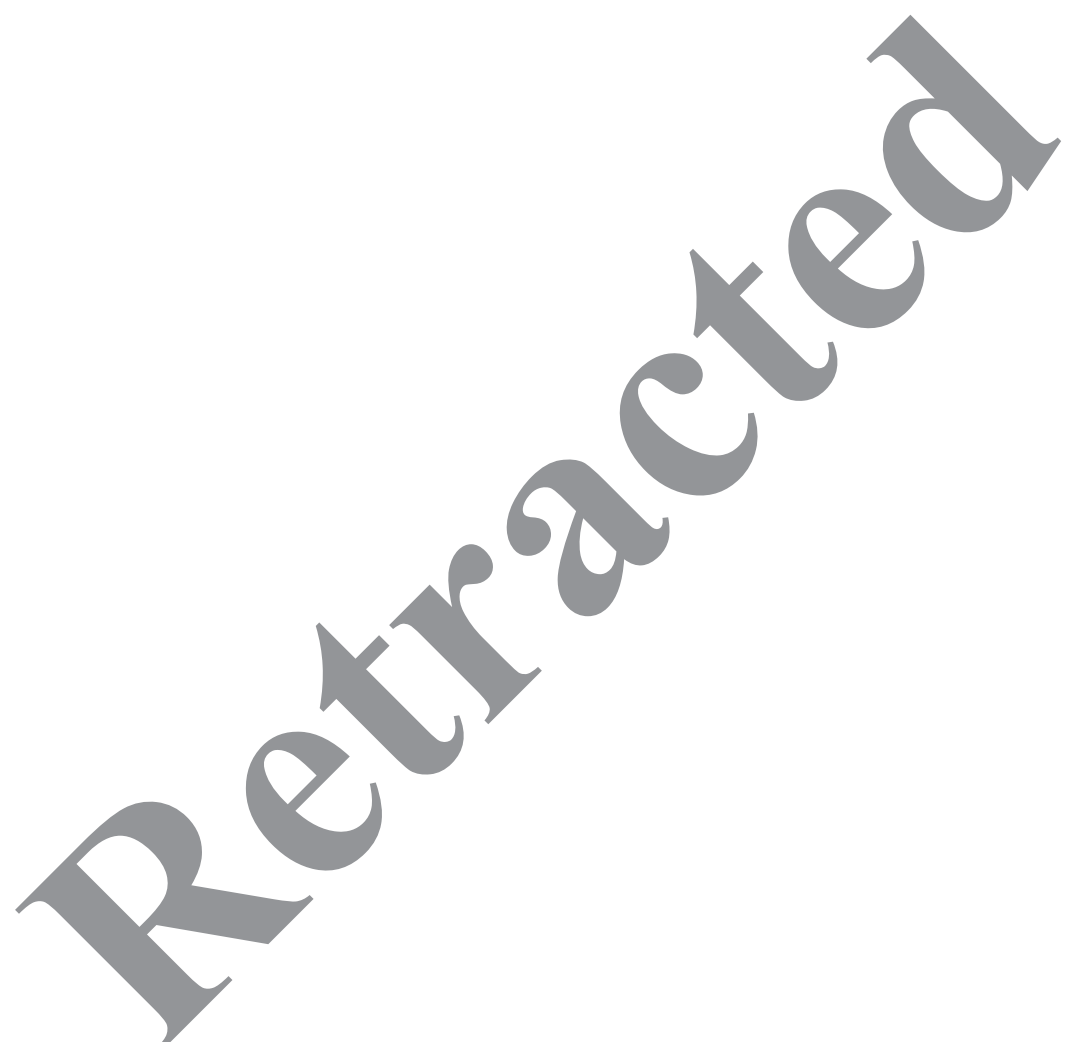

